\title{
Hypotensive and heart rate-lowering effects in rats receiving milk fermented by specific Lactococcus lactis strains
}

\author{
J. C. Rodríguez-Figueroa, A. F. González-Córdova, H. Astiazaran-García and B. Vallejo-Cordoba* \\ Centro de Investigación en Alimentación y Desarrollo A.C. (CIAD, A.C.), Carretera a La Victoria Km. O·6, Hermosillo, \\ Sonora 83304, Mexico \\ (Submitted 16 November 2011 - Final revision received 24 April 2012 - Accepted 24 April 2012 - First published online 1 July 2012)
}

\section{Abstract}

Previous studies have demonstrated that milk fermented by specific Lactococcus lactis strains significantly inhibits the activity of angiotensin I-converting enzyme (ACE). However, the relationship between the ACE inhibitor and its in vivo action has revealed discrepancies. Therefore, the aim of the present study was to investigate the antihypertensive and heart rate (HR)-lowering effect of milk fermented by specific L. lactis in a murine model. Spontaneously hypertensive male rats (271 (SD 14)g) were randomised into four treatment groups that were orally administered with milk fermented by L. lactis NRRL B-50571 or L. lactis NRRL B-50 572 at 35 or 50 mg protein/ kg body weight (BW), respectively. Further, two more groups were fed with different solutions as controls: a saline solution as the negative control and Captopril ${ }^{\mathrm{TM}}(40 \mathrm{mg} / \mathrm{kg}$ BW), a proven ACE inhibitor, as the positive control. Blood pressure and HR were monitored by the tail-cuff method before the treatments and at 2, 4,6 and $24 \mathrm{~h}$ post-oral administration. The results demonstrated that milk fermented by L. lactis NRRL B-50571 as well as by L. lactis NRRL B-50572 presented an important systolic and diastolic blood pressure- and HR-lowering effect. Thus, milk fermented by specific L. lactis strains may present potential benefits in the prevention and treatment of CVD associated with hypertension in humans.

Key words: Lactococcus lactis: Fermented milk: Antihypertensive effects: Functional food: Spontaneously hypertensive rats

Hypertension has become a serious health problem, which has been considered an important CVD risk factor, especially in developing countries ${ }^{(1)}$. The long-term regulation of blood pressure is associated with the rennin-angiotensin system. The conversion of angiotensin I into angiotensin II, a potent vasoconstrictor octapeptide, by the angiotensinconverting enzyme (ACE, EC 3.4.15.1) has long been known ${ }^{(2)}$. Hence, the inhibition of this enzyme can reduce high arterial blood pressure through ACE-inhibitory compounds.

Blood pressure is monitored by systolic blood pressure (SBP) and diastolic blood pressure (DBP). Brachial SBP is overall the best predictor of future cardiovascular risk for the entire hypertensive population. However, DBP must be measured in order to calculate pulse pressure, which has become a surrogate marker of central elastic large artery stiffness and a useful predictor of cardiovascular risk in the elderly population $^{(3,4)}$. On the other hand, heart rate (HR) is an important determinant of myocardial oxygen consumption and cardiac work. Several experimental lines of research have considered HR as an important risk factor for atherosclerosis. In fact, HR reduction may represent an important strategy for the treatment of patients with a wide range of cardiac disorders ${ }^{(5)}$. Therefore, SBP, DBP and HR measurements give a wide view related to cardiovascular disorders. Because of the high prevalence of hypertension and serious health consequences, lifestyle modifications, including dietary interventions, are recommended to help prevent and treat hypertension $^{(6)}$. Research with hypertensive animals ${ }^{(7)}$ and human subjects ${ }^{(8)}$ have indicated that milk peptides derived from casein and whey may have a hypotensive effect.

Milk proteins have received increased attention as potential ingredients in health-promoting functional foods. It is accepted that proteins from milk may act as precursors of biologically active peptides with different physiological effects on digestive, endocrine, cardiovascular, immune and nervous systems ${ }^{(9)}$. Indeed, it has been reported that an effective way to increase the amount of bioactive peptides in dairy products

Abbreviations: ACE, angiotensin I-converting enzyme; BW, body weight; DBP, diastolic blood pressure; HR, heart rate; NRRL B-50 571-3, milk fermented by Lactococcus lactis NRRL B-50 571 (35 mg protein/kg body weight); NRRL B-50 572-3, milk fermented by Lactococcus lactis NRRL B-50 572 (35 mg protein/kg body weight); NRRL B-50 571-5, milk fermented by Lactococcus lactis NRRL B-50 571 ( 50 mg protein/kg body weight); NRRL B-50 572-5, milk fermented by Lactococcus lactis NRRL B-50 572 (50 mg protein/kg body weight); SBP, systolic blood pressure; SHR, spontaneously hypertensive rat.

*Corresponding author: B. Vallejo-Cordoba, email vallejo@ciad.mx 
is by milk fermentation with highly proteolytic strains of lactic acid bacteria $^{(10)}$. Lactic acid bacteria growth in milk is dependent on specific proteolytic and peptidolytic systems for the generation of free amino acids and free peptides as a source of $\mathrm{N}^{(11)}$. In fact, several studies have suggested that peptides released by Enterococcus faecalis strains from milk proteins were able to decrease arterial blood pressure in spontaneously hypertensive rats $(\mathrm{SHR})^{(7,12)}$.

L. lactis is one of the most well-studied lactic acid bacteria because of its importance as part of commercial starter cultures used in the manufacture of fermented dairy products ${ }^{(13)}$. It has been reported that $L$. lactis strains are able to improve the organoleptic characteristics of dairy products ${ }^{(14)}$. Previous studies in our laboratory have shown that specific L. lactis strains isolated from native ecosystems were able to produce remarkable aroma profiles in fermented milk $^{(15)}$. In addition, milk fermented by these specific strains was able to inhibit ACE activity. However, the antihypertensive effects of milk fermented by these specific $L$. lactis strains have not been investigated. Therefore, the objective of the present study was to evaluate the blood pressure- and HR-lowering effect of milk fermented by specific L. lactis strains in an animal model.

\section{Materials and methods}

\section{Strains and growth conditions}

L. lactis strains (NRRL B-50571 and NRRL B-50 572) were deposited at the Agricultural Research Service Culture Collection (NRRL) of the National Center for Agricultural Utilization Research (US Department of Agriculture Peoria, IL). Strains were routinely propagated in $10 \mathrm{ml}$ of sterile lactose $(5 \mathrm{~g} / \mathrm{l})$ $\mathrm{M} 17$ broth (DIFCO) and incubated at $30^{\circ} \mathrm{C}$ for $24 \mathrm{~h}$. Fresh cultures were obtained by repeating the same procedure. The initial starter culture of each L. lactis strain reached $10^{6}-10^{7}$ colony-forming units/ml as enumerated on M17 agar supplemented with lactose $(5 \mathrm{~g} / \mathrm{l})$.

\section{Manufacture of fermented milk samples}

Organic grade A non-fat dry milk from Organic Valley ${ }^{\circledR}$ was reconstituted in purified water at $10 \%(\mathrm{w} / \mathrm{w})$ and sterilised $\left(100^{\circ} \mathrm{C}, 20 \mathrm{~min}\right)$. Every single specific L. lactis strain was inoculated with a loop in sterilised milk with an initial bacterial population of $7-8 \log$ colony-forming units $/ \mathrm{ml}$ as pre-cultures. The inoculated milk was incubated for $12 \mathrm{~h}$ at $30^{\circ} \mathrm{C}$. Pre-cultures were added $(3 \%, \mathrm{v} / \mathrm{v})$ to the sterilised milk to obtain the different 3-litre fermented milk batches. Incubation was performed at $30^{\circ} \mathrm{C}$ and stopped at $48 \mathrm{~h}$ by pasteurisation at $75^{\circ} \mathrm{C}$ for $1 \mathrm{~min}$ to obtain the samples. Samples of specific L. lactis-fermented milk for the single-dose bioassay were obtained by centrifugation at $20000 \mathrm{~g}$ (J2-21 rotor; Beckman) for $10 \mathrm{~min}$ at $0^{\circ} \mathrm{C}$. The supernatants were collected and lyophilised with a freeze-dryer (Labconco). All samples were kept at $4^{\circ} \mathrm{C}$ until use for further analysis. Total protein (Method 960.52 Official Method of Analysis of the Association of Official Analytical Chemists (AOAC), 1998), $\mathrm{Ca}, \mathrm{Mg}, \mathrm{K}$ (EPA 3052), total fat (Method 942.05 AOAC, 1998) and lactose (Method 930.28 AOAC, 1998) contents of the lyophilised whey were evaluated (Table 1).

\section{Experimental protocol with spontaneously hypertensive rats}

A total of forty-two male SHR (4-5 weeks old, 72 (SD 7) g body weight (BW)) were obtained from Harlan Laboratories, Inc. SHR were weaned for 8 weeks and their SBP monitored during this period. The rats were randomly housed in pairs per cage at $21 \pm 2^{\circ} \mathrm{C}, 12 \mathrm{~h}$ light-dark cycles and $52 \pm 6 \%$ relative humidity, with an ad libitum intake of a standard diet (Teklad; Harlan Laboratories, Inc.) and purified water. SHR (12-13 weeks old, 271 (SD 14) g BW) were divided into six groups of seven rats $(n 7)$ : oral administration of saline as the negative control and Captopril ${ }^{\mathrm{TM}}$ (a proven hypotensive drug, $40 \mathrm{mg} / \mathrm{kg} \mathrm{BW}$ ) as the positive control. The animals were weighed before oral administration in order to prepare the corresponding amount of lyophilised whey/kg animal weight. The lyophilised whey fractions of milk fermented by L. lactis NRRL B-50572 or NRRL B-50571 were dissolved in $0.8 \mathrm{ml}$ of saline. The treatments were NRRL B-50572-3 (35 mg protein/kg BW), NRRL B-50 572-5 (50 mg protein/kg $\mathrm{BW}$ ), NRRL B-50571-3 (35 mg protein/kg BW) and NRRL B-50 571-5 (50 mg protein/kg BW).

Conscious SHR received a single dose through a cannula between 08.30 and 09.30 hours to eliminate circadian cycles. The animals were restrained in the warming chamber for $20 \mathrm{~min}$ at $32^{\circ} \mathrm{C}$ to detect pulsations through the caudal artery. SBP, DBP as well as HR were monitored before

Table 1. Chemical composition of the whey fractions obtained from milk fermented by specific Lactococcus lactis strains (Mean values and standard deviations)

\begin{tabular}{|c|c|c|c|c|c|c|c|c|}
\hline & \multicolumn{2}{|c|}{ NRRL B-50 571-3 } & \multicolumn{2}{|c|}{ NRRL B-50 572-3 } & \multicolumn{2}{|c|}{ NRRL B-50 571-5 } & \multicolumn{2}{|c|}{ NRRL B-50 572-5 } \\
\hline & Mean & SD & Mean & SD & Mean & SD & Mean & SD \\
\hline Protein (mg/dosage) & 35 & 3 & 35 & 3 & 50 & 3 & 50 & 3 \\
\hline Fat (g/dosage) & \multicolumn{2}{|c|}{ ND } & \multicolumn{2}{|c|}{ ND } & \multicolumn{2}{|c|}{ ND } & \multicolumn{2}{|c|}{ ND } \\
\hline Lactose (mg/dosage) & 1250 & 30 & 1310 & 20 & 1790 & 43 & 1870 & 28 \\
\hline $\mathrm{Ca}$ (mg/dosage) & 3.7 & 0.01 & 3.6 & 0.03 & $5 \cdot 3$ & 0.02 & $5 \cdot 23$ & 0.04 \\
\hline $\mathrm{K}$ (mg/dosage) & 4.4 & 0.1 & $4 \cdot 3$ & 0.1 & $6 \cdot 3$ & 0.2 & $6 \cdot 2$ & 0.1 \\
\hline $\mathrm{Mg}$ (mg/dosage $)$ & 0.3 & 0.01 & 0.3 & 0.03 & 0.5 & 0.02 & 0.4 & 0.1 \\
\hline
\end{tabular}

NRRL B-50571-3, milk fermented by L. lactis NRRL B-50571 (35 mg protein/kg BW); NRRL B-50 572-3, milk fermented by L. lactis NRRL B-50 572 (35 mg protein/kg BW); NRRL B-50571-5, milk fermented by L. lactis NRRL B-50571 (50 mg protein/kg BW); NRRL B-50 572-5, milk fermented by L. lactis NRRL B-50572 (50 mg protein/kg BW); ND, not detected. 
administration and at 2, 4, 6 and $24 \mathrm{~h}$ post-administration. Measurements were taken five times using the non-invasive blood pressure system using a photoelectric sensor, amplifier, automatic inflation cuff and software (Model 229; IITC). The animal experimental procedures were done following the guidelines and supervision of the Centro de Investigación en Alimentación y Desarrollo, A.C. Committee of Ethics for scientific research.

\section{Statistical analysis}

Data normality was evaluated as a prerequisite before oneway ANOVA was carried out. Differences among means were assessed by Fisher's least significant difference multiple comparison test and considered significant when $P<0.05$. Data analyses were performed using the NCSS 2007 statistical program (NCSS Inc.).

\section{Results}

Antihypertensive effects of milk fermented by specific Lactococcus lactis strains

Fig. 1 shows that SHR became hypertensive when they were 7 weeks old. The rats presented with $>150 \mathrm{mmHg}$ SBP for more than 4 weeks, which is a prerequisite for being considered hypertensive ${ }^{(16)}$.

SBP changes are shown in Fig. 2(a). The results showed maximal SBP reductions at $6 \mathrm{~h}$ post-oral administration. SHR treated with the whey fractions of milk fermented by L. lactis NRRL B-50572-5 and L. lactis NRRL B-50571-3 showed a more relevant decrement in SBP (16.7 (SEM 3.5) $\mathrm{mmHg}$ and $17 \cdot 7$ (SEM 4.0) $\mathrm{mmHg}$, respectively), although the treatments were not significantly different $(P>0 \cdot 05)$.

The maximum decrease at $6 \mathrm{~h}$ was observed in the animals treated with Captopril ${ }^{\mathrm{TM}}$, which was significantly different from the other treatments $(P<0.05)$. However, the SBP measurements $24 \mathrm{~h}$ post-administration showed that SHR treated with the whey fraction of milk fermented by L. lactis NRRL B-50 572-5 showed a SBP of $4.3 \mathrm{mmHg}$ less than the rats that

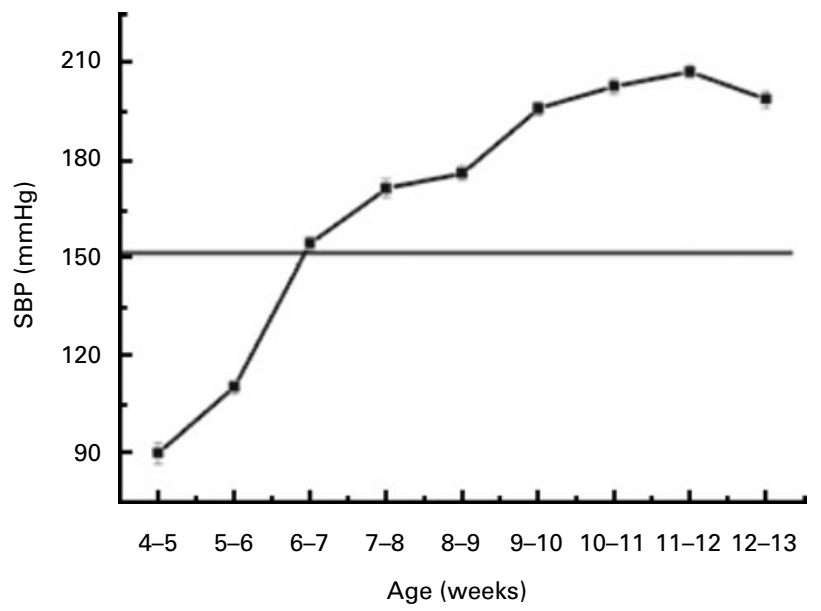

Fig. 1. Development of hypertension with age. SBP (- - - ), systolic blood pressure. Values are means, with their standard errors represented by vertical bars $(n 42)$.

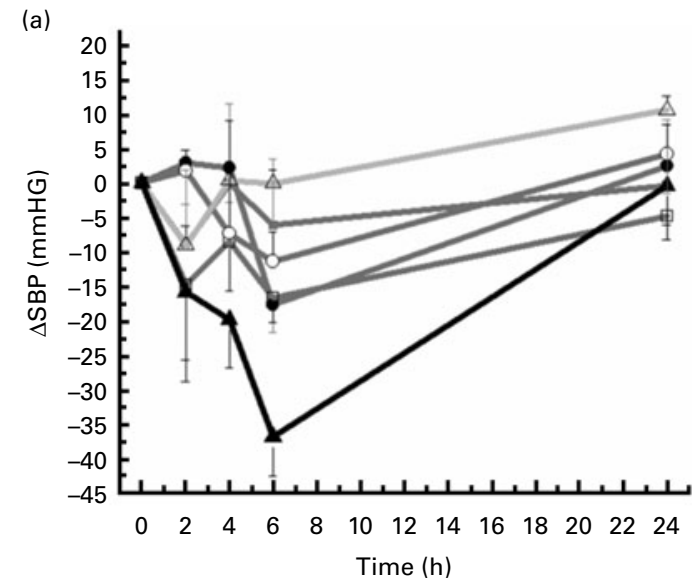

(b)

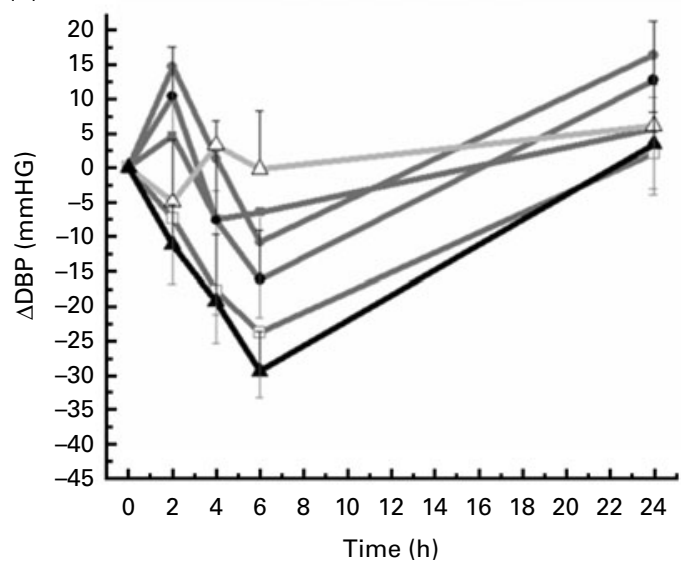

(c)

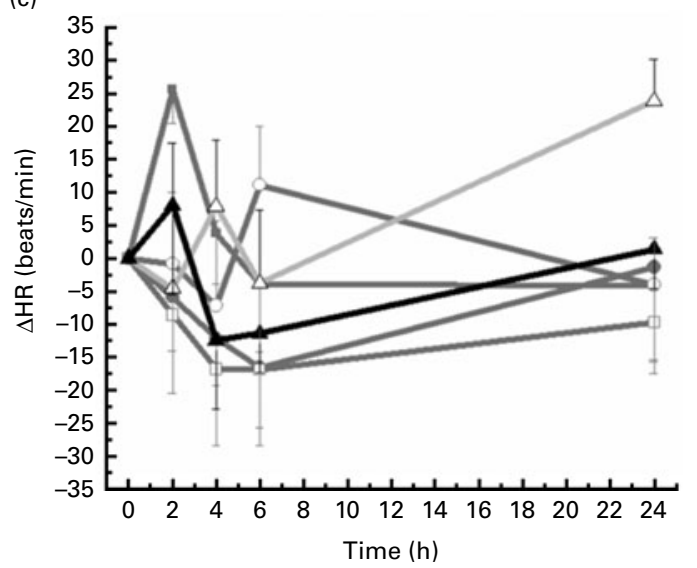

Fig. 2. Blood pressure- and heart rate (HR)-lowering effects in spontaneously hypertensive rats (SHR) treated with milk fermented by specific Lactococcus lactis strains: (a) systolic blood pressure (SBP), (b) diastolic blood pressure (DBP) and (c) HR. $\leftarrow$, Captopril ${ }^{\mathrm{TM}}$ (positive control); $\triangle$, saline (negative control); - - , whey fraction of milk fermented by L. lactis NRRL B-50 572-3 (35 mg protein/kg body weight (BW)); $-\square-$, whey fraction of milk fermented by L. lactis NRRL B-50571-3 (35 mg protein/kg BW); -- , whey fraction of milk fermented by L. lactis NRRL B-50572-5 (50 mg protein $/ \mathrm{kg} \mathrm{BW);}$ $-\bigcirc-$, whey fraction of milk fermented by L. lactis NRRL B-50571-5 (50 mg protein $/ \mathrm{kg} \mathrm{BW).} \mathrm{Values} \mathrm{are} \mathrm{means,} \mathrm{with} \mathrm{their} \mathrm{standard} \mathrm{errors} \mathrm{represented}$ by vertical bars ( $n$ 42). NRRL B-50571-3, milk fermented by L. lactis NRRL B-50571 (35 mg protein/kg BW); NRRL B-50572-3, milk fermented by L. lactis NRRL B-50572 (35 mg protein/kg BW); NRRL B-50571-5, milk fermented by $L$. lactis NRRL B-50571 (50 mg protein $/ \mathrm{kg}$ BW); NRRL B-50 572-5, milk fermented by L. lactis NRRL B-50 572 (50 mg protein/kg BW). 


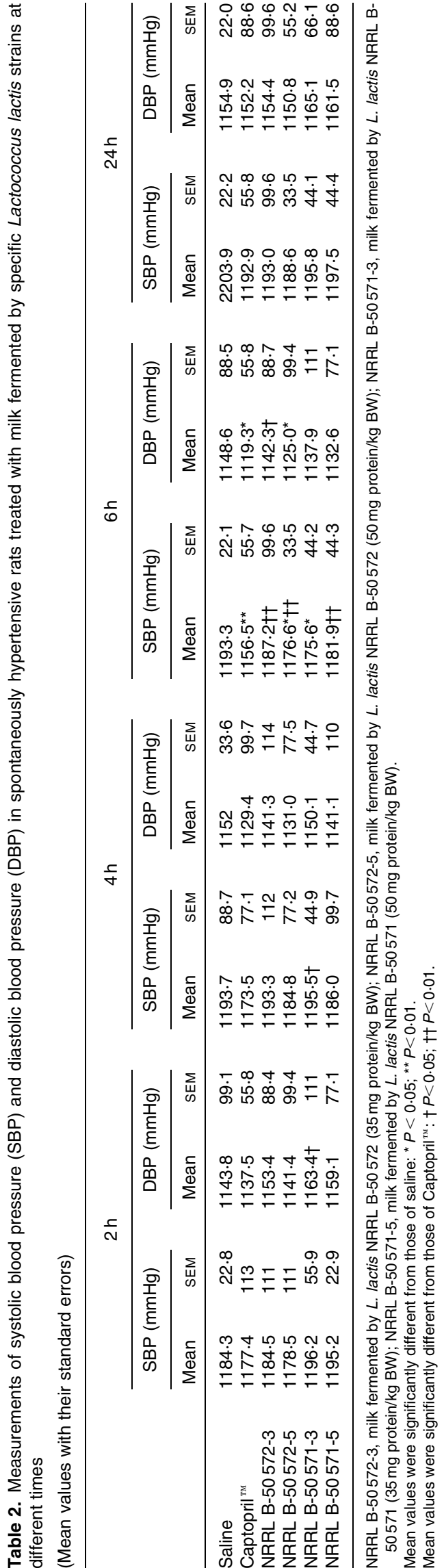

were treated with Captopril ${ }^{\mathrm{TM}}$. These results suggest that L. lactis NRRL B-50 572-5-fermented milk may have an important residual blood pressure-reducing effect. Moreover, a remarkable decrement in SBP of $15.3 \mathrm{mmHg}$ was found between SHR that received the whey fraction of milk fermented by L. lactis NRRL B-50 572-5 and those treated with saline. Hence, blood pressure measurements suggested the absence of a dose-dependent relationship between the protein content of the whey fraction corresponding to milk fermented by L. lactis NRRL B-50 571 and its ability to reduce SBP, whereas the whey fraction of milk fermented by L. lactis NRRL B- 50572 was dose-dependent.

Fig. 2(b) shows a reduction of DBP in SHR caused by the oral administration of the whey fraction of milk fermented by specific $L$. lactis strains. The highest decrement in DBP was observed at $6 \mathrm{~h}$ post-oral administration. At the same time, no significant difference was found $(P>0.05)$ when SHR were treated with the whey fraction of milk fermented by L. lactis NRRL B-50571 at any protein content or with the whey fraction of milk fermented by L. lactis NRRL B-50 572-5. The whey fractions from milk fermented by L. lactis NRRL B-50571 as well as by L. lactis NRRL B-50572 presented an important dose-dependent antihypertensive effect with DBP measurements. Although Captopril ${ }^{\mathrm{TM}}$ generated a maximum DBP reduction with each measurement, there was no significant difference $(P>0.05)$ with the hypotensive effect of the whey fraction of milk fermented by L. lactis NRRL B-50 572-5.

HR reductions in treated SHR at 2, 4, 6 and $24 \mathrm{~h}$ are shown in Fig. 2(c). No significant difference $(P>0.05)$ in HR was observed in rats administered with whey fractions from milk fermented by L. lactis NRRL B-50572-5, NRRL B-50571-3, Captopril $^{\mathrm{TM}}$. As with SBP and DBP, the lowest HR values were found at $6 \mathrm{~h}$ post-administration of the treatments. In fact, SHR treated with the whey fraction of milk fermented by L. lactis NRRL B-50571-3 as well as by L. lactis NRRL B-50572-5 showed a maximal decrement in HR (16.6 (SEM 9.2) and 16.9 ( $\operatorname{sem} 11.5)$ beats/min, respectively). Moreover, a significant $(P<0.05)$ HR decrement $(33.4$ beats $/ \mathrm{min})$ was found in SHR that received the whey fraction from L. lactis NRRL B-50 572-5-fermented milk when compared with the saline treatment at the end of the $24 \mathrm{~h}$ post-oral administration.

Tables 2 and 3 show the initial blood pressure and HR values, respectively. A notorious difference in SBP values at $2 \mathrm{~h}(184.3$ (SEM 2.8 ) $\mathrm{mmHg}$ ) and $24 \mathrm{~h}$ (203.9 (SEM 2.2) $\mathrm{mmHg}$ ) was found post-administration in SHR treated with the saline solution. These results may be due to the increasing hypertension of SHR at this age. A similar result was found in HR measurements. SHR administered with saline showed an HR of 383.6 (SEM 22.1) beats/min $2 \mathrm{~h}$ after oral ingestion compared with 412.0 (SEM 6.3) beats/min $24 \mathrm{~h}$ later. The dispersion of the data may be due to the fact that SBP, DBP and HR measurements were obtained when SHR were conscious.

\section{Discussion}

To date, the SHR is one of the most widely utilised animal model to study essential hypertension and its associated metabolic disorders ${ }^{(17)}$. Some of the advantages of using SHR 
Table 3. Measurements of heart rate (HR) in spontaneously hypertensive rats treated with milk fermented by specific Lactococcus lactis strains at different times

(Mean values with their standard errors)

\begin{tabular}{|c|c|c|c|c|c|c|c|c|}
\hline & \multicolumn{2}{|c|}{$2 \mathrm{~h}$} & \multicolumn{2}{|c|}{$4 h$} & \multicolumn{2}{|c|}{$6 \mathrm{~h}$} & \multicolumn{2}{|c|}{$24 \mathrm{~h}$} \\
\hline & \multicolumn{2}{|c|}{ HR (beats/min) } & \multicolumn{2}{|c|}{ HR (beats/min) } & \multicolumn{2}{|c|}{$\mathrm{HR}$ (beats/min) } & \multicolumn{2}{|c|}{ HR (beats/min) } \\
\hline & Mean & SEM & Mean & SEM & Mean & SEM & Mean & SEM \\
\hline Saline & 383.6 & $22 \cdot 1$ & $396 \cdot 1$ & $10 \cdot 0$ & 384.3 & $11 \cdot 1$ & $412 \cdot 0$ & $6 \cdot 3$ \\
\hline Captopril $^{\mathrm{TM}}$ & $396 \cdot 2$ & $13 \cdot 6$ & $375 \cdot 7$ & $10 \cdot 4$ & $376 \cdot 7$ & $6 \cdot 0$ & 389.5 & 5.9 \\
\hline NRRL B-50572-3 & $413 \cdot 8$ & $5 \cdot 1$ & $392 \cdot 0$ & $7 \cdot 7$ & $384 \cdot 3$ & $5 \cdot 1$ & $384 \cdot 0$ & $11 \cdot 3$ \\
\hline NRRL B-50572-5 & 379.6 & 11.9 & 371.3 & 11.6 & 371.3 & 11.5 & $378.4^{*}$ & 5.9 \\
\hline NRRL B-50 571-3 & 382.2 & $8 \cdot 2$ & 375.9 & $7 \cdot 0$ & 371.6 & $9 \cdot 2$ & $386 \cdot 8$ & $16 \cdot 2$ \\
\hline NRRL B-50 571-5 & 387.3 & $10 \cdot 8$ & 381.0 & $12 \cdot 8$ & $399 \cdot 3$ & 8.9 & $384 \cdot 1$ & $7 \cdot 2$ \\
\hline
\end{tabular}

NRRL B-50 572-3, milk fermented by L. lactis NRRL B-50 572 (35 mg protein/kg BW); NRRL B-50 572-5, milk fermented by L. lactis NRRL B-50 572 (50 mg protein/kg BW); NRRL B-50 571-3, milk fermented by L. lactis NRRL B-50 571 (35 mg protein/kg BW); NRRL B-50 571-5, milk fermented by L. lactis NRRL B-50 571 (50 mg protein/kg BW).

${ }^{*}$ Mean value was significantly different from that of saline $(P<0.05)$.

strains to evaluate primary hypertension are related to the ability to provide new insights into relevant mechanisms for blood pressure control in rodents and humans, and to the fact that many genes identified in animal models have been extensively studied in human subjects. Probably the most important issue of using SHR to evaluate the antihypertensive effects of specific substances is the feasibility to determine and characterise the influence of specific treatments establishing a close relationship between an antihypertensive substance and a hypotensive effect ${ }^{(18)}$. In recent years, peptides derived from food protein substrates such as milk, egg, fish, sesame, pea, sake, rice and maize have demonstrated important antihypertensive activity $^{(19)}$.

At the beginning of the present study, we knew that specific L. lactis strains were able to ferment milk with the ability to inhibit the activity of the ACE, which is associated with the reduction in blood pressure. In fact, these previous in vitro studies have shown the relevant capacity of L. lactis NRRL B-50571 and L. lactis NRRL B-50572 to hydrolyse milk proteins to exert antihypertensive activity. On the other hand, based on the complexity of living organisms, studies showing a clear direct correlation between in vitro and in vivo hypotensive activity have not been reported ${ }^{(10)}$. Therefore, it was necessary to evaluate the antihypertensive effect of milk fermented by specific L. lactis strains in an animal model.

The present study demonstrated the ability of specific L. lactis strains to ferment milk with blood pressure- and HR-lowering effect in vivo. The remarkable hypotensive effect as well as the HR reduction were observed at $6 \mathrm{~h}$ post-oral administration. In fact, it has been reported that there were maximal SBP and DBP reductions in SHR treated with the whey fraction of milk fermented by $E$. faecalis at 4 and $6 \mathrm{~h}$ post-administration ${ }^{(7)}$.

An association of specific minerals with blood pressure reduction in SHR has been reported ${ }^{(20,21)}$. Therefore, it was necessary to determine the chemical composition of whey fractions from fermented milk (Table 1). Indeed, it has been reported that there was a decrement in systolic and DBP in SHR fed with an enriched Ca diet (2.5\%) during a long-term experiment ${ }^{(22)}$. However, in the present experiment, the dose with the highest $\mathrm{Ca}$ concentration corresponded to less than $1 \%$ of the SHR diet. On the other hand, the content of $\mathrm{Mg}$ in the SHR diet may play a role in hypertension. Sipola et $a{ }^{(23)}$ did not report a blood pressure-lowering effect associated with Mg content in SHR after a 12-week treatment. It is important to note that the amount of $\mathrm{Mg}$ present in milk fermented by Lactobacillus belveticus $(0.33 \mathrm{mg} / \mathrm{g})$ in that study was similar to that found in milk fermented by specific L. lactis in the present study. Thus, the effect of $\mathrm{Ca}$ and $\mathrm{Mg}$ content on blood pressure reduction in SHR of the present study may not be important.

In the present study, two protein concentrations (35 or $50 \mathrm{mg} / \mathrm{kg} \mathrm{BW}$ ) were administered to SHR by a single dose. Hence, according to the results shown in Fig. 2(a), milk fermented by L. lactis NRRL B-50572 was dose-dependent. Nakamura et al. ${ }^{(24)}$ evaluated the capacity of milk fermented by L. helveticus and Saccharomyces cerevisiae to reduce SBP. SHR received $34 \mathrm{mg}$ protein $/ \mathrm{kg}$ BW of the whey fraction, resulting in a decrement of 21.8 (SEM 4.2) $\mathrm{mmHg}$. Masuda et $a l .{ }^{(25)}$ also used the same $L$. helveticus and $S$. cerevisiae strains to ferment milk by increasing the protein content to $68 \mathrm{mg} / \mathrm{kg}$ BW followed by a reduction in blood pressure to $-26 \cdot 4$ ( $\operatorname{sem} 3 \cdot 1) \mathrm{mmHg}$. These findings showed a dosedependent relationship.

Muguerza et $a l .{ }^{(7)}$ also evaluated the antihypertensive effect of milk fermented by E. faecalis in SHR. In this case, a single dose of milk fermented by E. faecalis CECT 5727 and CECT 5728 presented a maximal DBP reduction of 34.8 (SEM 4.5) mmHg. Chen et al. ${ }^{(26)}$ measured the antihypertensive effect of fresh low-fat milk fermented by five mixed lactic acid bacteria. The DBP value reported was $-21.5 \mathrm{mmHg}$ after 8 weeks of oral administration. Similar results were found in the present study for SHR treated with a single dose of milk fermented by L. lactis NRRL B-50 572-5 $(-23.9$ ( $\operatorname{sem} 9 \cdot 4) \mathrm{mmHg}$ ).

On the other hand, it is important to note that a maximal SBP reduction $(17.7$ (SEM 4.0 ) $\mathrm{mmHg}$ ) was observed in SHR treated with the lowest dose of whey fraction from milk 
fermented by L lactis NRRL B-50 571-3 (35 mg protein/kg BW), although this treatment was not significantly $(P<0.05)$ different from milk fermented by L. lactis NRRL B-50571-5 (50 mg protein $/ \mathrm{kg} \mathrm{BW}$ ). The dose-dependent effect for the whey fraction produced by NRRL B-50 572 but not for the whey fraction produced by NRRL B-50571 might be related to their chemical composition. It has been reported that there is a close relationship between peptide structure and its hypertensive effect ${ }^{(10)}$.

HR is a major determinant of myocardial oxygen consumption and cardiac work. Indeed, high HR has been considered as an important risk factor for atherosclerosis; therefore, its reduction may represent an important strategy for the treatment of patients with a wide range of cardiac disorders ${ }^{(5)}$. In the present study, an evident reduction in the HR of SHR was observed after the single-dose treatment (Fig. 2(c)). The whey fraction corresponding to milk fermented by L. lactis NRRL B-50 571-3 decreased HR by 16.6 (SEM 9.2) beats/min, while the whey fraction of milk fermented by L. lactis NRRL B-50 572-5 decreased HR by 16.9 (SEM 11.5) beats/min at $6 \mathrm{~h}$ after oral administration. On the other hand, Captopril ${ }^{\mathrm{TM}}$ decreased HR by 11.4 (SEM 5.9) beats/min. To the best of our knowledge, this is the first report on the blood pressureand HR-lowering effect of whey fractions obtained from milk fermented by L. lactis.

In conclusion, the present study demonstrated the relevant blood pressure- and HR-lowering effect of milk fermented by specific L. lactis strains on SHR. Moreover, previous research in our laboratory reported the capacity of these strains to biogenerate interesting aroma profiles. Thus, whey fractions from milk fermented by specific L. lactis strains may be used as a functional ingredient or food with important advantages in the prevention and treatment of CVD associated with hypertension. Ongoing research is being carried out to identify the sequences of the antihypertensive peptides present in the whey fraction and their mechanism of absorption.

\section{Acknowledgements}

We would like to thank María del Carmen Estrada and Rodrigo Pacheco for their technical support during the experiment. This study was supported by CONACYT (projects 42340-Z and 134295). The authors' responsibilities were as follows: B. V.-C. developed the overall research plan in collaboration with A. F. G.-C.; H. A.-G. provided the technical expertise; J. C. R.-F. designed and conducted the experiments and wrote the manuscript. All authors declare that there is no conflict of interests.

\section{References}

1. Anadón A, Martínez MA, Ares I, et al. (2010) Acute and repeated dose (4 weeks) oral toxicity studies of two antihypertensive peptides, RYLGY and AYFYPEL, that correspond to fragments $(90-94)$ and $(143-149)$ from $\alpha_{\mathrm{s} 1}$-casein. Food Chem Toxicol 48, 1836-1845.

2. Skeggs LT, Kahn JR \& Shumway NP (1956) The preparation and function of the hypertension-converting enzyme. $J$ Exp Med 103, 295-299.
3. Stanley SF (2007) The importance of diastolic blood pressure in predicting cardiovascular risk. J Am Soc Hypertens $\mathbf{1}$, $82-93$

4. Safar ME, Levy BL \& Struijker-Boudier HAJ (2003) Current perspectives on arterial stiffness and pulse pressure in hypertension and cardiovascular diseases. Circulation 107, 2864-2869.

5. Palatini P (2009) Elevated heart rate in cardiovascular diseases: a target for treatment? Prog Cardiovasc Dis 52, 46-60.

6. Chobanian AV, Bakris GL, Black HR, et al. (2003) The Seventh Report of the Joint National Committee on Prevention, Detection, Evaluation, and Treatment of High Blood Pressure: the JNC 7 report. JAMA 289, 2560-2572.

7. Muguerza B, Ramos M, Sánchez E, et al. (2006) Antihypertensive activity of milk fermented by Enterococcus faecalis strains isolated from raw milk. Int Dairy J 16, 61-69.

8. Aihara K, Kajimoto O, Hirata $\mathrm{H}$, et al. (2005) Effect of powdered fermented milk with Lactobacillus helveticus on subjects with high-normal blood pressure or mild hypertension. J Am Coll Nutr 24, 257-265.

9. Korhonen H (2009) Milk-derived bioactive peptides: from science to applications. J Funct Foods 1, 177-187.

10. López-Fandiño R, Otte J \& van Camp J (2006) Physiological, chemical technological aspects of milk-protein-derived peptides with antihypertensive and ACE-inhibitory activity. Int Dairy J 16, 1277-1293.

11. Hugenholtz J (2008) The lactic acid bacterium as a cell factory for food ingredient production. Int Dairy J 18, 466-475.

12. Quirós A, Ramos M, Muguerza B, et al. (2007) Identification of novel antihypertensive peptides in milk fermented with Enterococcus faecalis. Int Dairy J 17, 33-41.

13. Odamaki T, Yonezawa S, Sugahara H, et al. (2011) A one step genotypic identification of Lactococcus lactis subspecies at the species/strain levels. Syst Appl Microbiol 34, 429-434.

14. Ayad Eman HE (2009) Starter culture development for improving safety and quality of Domiati cheese. Food Microbiol 26, 533-541.

15. Gutiérrez-Méndez N, Vallejo-Cordoba B, González-Córdova $\mathrm{AF}$, et al. (2008) Evaluation of aroma generation of Lactococcus lactis with an electronic nose and sensory analysis. J Dairy Sci 91, 49-57.

16. Okamoto K \& Aoki K (1963) Development of a strain of spontaneously hypertensive rats. Jpn Circ Soc 27, 282-293.

17. Pavenec M \& Kurtz T (2010) Recent advances in genetics of spontaneously hypertensive rat. Curr Hypertens Rep 12, 5-9.

18. Saavedra J (2009) Opportunities and limitations of genetic analysis of hypertensive rat strains. $J$ Hypertens $\mathbf{2 7}$, 1129-1133.

19. Hong F, Ming L, Yi S, et al. (2008) The antihypertensive effect of peptides: a novel alternative to drugs? Peptides 29, 1062-1071.

20. Whelton P, He J, Cutler J, et al. (1997) Effects of oral potassium on blood pressure. Meta-analysis of randomized controlled clinical trials. JAMA 277, 1624-1632.

21. Adachi M, Nara Y, Mano M, et al. (1994) Effect of dietary magnesium supplementation on intralymphocytic free calcium and magnesium in stroke-prone spontaneously hypertensive rats. Clin Exp Hypertens 16, 317-326.

22. Civantos B \& Aleixandre A (2004) Blood pressure and $\alpha$-vascular reactivity in hypertensive rats treated with amlodipine and dietary Ca. Eur J Pharmacol 489, 101-110.

23. Sipola M, Finckenberg P, Santisteban J, et al. (2001) Longterm of milk peptides attenuates development of hypertension in spontaneously hypertensive rats. J Physiol Pharmacol 52, $745-754$. 
24. Nakamura Y, Yamamoto N, Sakai K, et al. (1995) Antihypertensive effect of sour milk and peptides isolated from it that are inhibitors to angiotensin I-converting enzyme. J Dairy Sci 78, 1253-1257.

25. Masuda O, Nakamura Y \& Takano T (1996) Antihypertensive peptides are present in aorta after oral administration of sour milk containing these peptides to spontaneously hypertensive peptides. J Nutr 126, 3063-3068.

26. Chen GW, Tsai JS \& Pan SB (2007) Purification of angiotensin I-converting enzyme inhibitory peptides and antihypertensive effect of milk produced by protease-facilitated lactic fermentation. Int Dairy J 17, 641-647. 